\title{
Academic-Industry Research Partnerships: an Emerging Opportunity or Just Smoke and Mirrors?
}

\author{
Michael Hochman, MD, MPH' and Rachael Bedard, $M D^{2}$ \\ 'David Geffen School of Medicine, UCLA, Los Angeles, CA, USA; ${ }^{2}$ Icahn School of Medicine at Mount Sinai, New York, NY, USA.
}

J Gen Intern Med 31(2):149-50

DOI: $10.1007 / \mathrm{s} 11606-015-3527-8$

() Society of General Internal Medicine 2015

I $\mathrm{t}$ is a time of famine for clinical research, and academic investigators have had to hunt for viable funding sources. While inflation-adjusted public funding for biomedical research has declined over the past two decades, private industry's share of the funding pie has increased by $13 \%{ }^{1}$ The pharmaceutical industry has historically been eager to partner with academic investigators both to tap the academic talent pool and to enhance the credibility of its conclusions. In this month's issue of the JGIM, Tierney et al. consider situations in which academic-industry partnerships might be both ethical and mutually beneficial. ${ }^{2}$

In theory, appropriately regulated academic-industry partnerships could be a practical way to compensate for the shortfall in public research funding. Unfortunately, wellpublicized examples of industry tampering with results, thwarting the publication of negative trials, and concealing adverse effects from regulators and the public have highlighted the potential for ethical violations in industry-funded research. ${ }^{3}$ Tierney et al. state the problem plainly: "The goal of research funding by for-profit companies is maximizing income to their shareholders; increased knowledge and enhanced care, if they happen at all, are byproducts of the profit motive."

But, they argue, such pitfalls might be avoided with formal agreements between private companies and academic institutions and with stringent regulatory oversight. They describe one such partnership between the Regenstrief Institute in Indiana and Merck, Sharp \& Dohme that is overseen by the Indiana University Center for Bioethics. This oversight includes guaranteeing the right of academic investigators to publish all results regardless of outcome. The authors also advocate for "minimizing bias through rigorous studies devised, conducted and reported by academic investigators whose income is not tied to the drug being evaluated."

While such strategies may reduce overt research misconduct, there are other insidious ways that industry involvement can bias clinical research. Commercial entities presumably fund research in the hopes of generating data favorable to their

Published online October 9, 2015 products, and as a result may focus on commercially important questions of lower clinical importance. There are myriad examples of commercially funded studies led by academic researchers with full authority to interpret and publish the results and even design the methodology, but which do not advance clinical knowledge because they focus on questions of dubious clinical importance.

Take, for example, a recent Merck-funded randomized placebo-controlled trial conducted by academic investigators and published in the New England Journal of Medicine, which examined the effects of sitagliptin (Januvia), a DPP4 inhibitor used for treating diabetes. ${ }^{4}$ Over the past several years, sitagliptin has become one of the top- 25 pharmaceuticals in sales in the US, ${ }^{5}$ yet data on its efficacy with regard to clinically important outcomes are scant, and there is a need for high-quality research on this medication. The Merckfunded trial, with 15,000 patients, could have yielded insights into the utility of sitagliptin. But it didn't. Instead, the study focused on addressing concerns raised by the Food and Drug Administration about sitagliptin's cardiovascular safety. Reassuringly, the trial concluded that sitagliptin is noninferior to placebo with respect to cardiovascular outcomes. But the study failed to address the more basic and important question: is sitagliptin better than placebo (or alternative active therapies) with respect to the key complications of diabetes? Shockingly, in this large, well-designed trial, the researchers neglected to analyze the impact of sitagliptin on retinopathy, neuropathy, or nephropathy, and the study found no benefit with respect to cardiovascular outcomes.

When commercial sponsors drive the direction of research, they may also surreptitiously promote their products. Tierney et al. cite a commercially funded trial published in a highimpact journal that compared three antidepressant medications as an example of a successful academic-industry collaboration. ${ }^{6}$ Yet, notably, this trial failed to include a nonpharmacologic therapy arm consisting of patients receiving psychotherapy, thus implicitly promoting pharmacotherapy despite guidelines indicating that psychotherapy is an equally appropriate first-line option for mild to moderate depression. ${ }^{7}$

Tierney et al. also suggest that academic-industry partnerships may promote comparative effectiveness research, like the antidepressant trial noted above, since commercial sponsors may be interested in demonstrating that their products are superior to those of competitors. But the evidence does not bear this out. A recent analysis led by one of us $(\mathrm{MH})$ found 
that industry-funded medication studies are much less likely than similar studies funded by public and not-for-profit entities to generate the comparative effectiveness studies that clinicians and patients need to guide important clinical decisions. In addition to the fact that commercial entities fund the majority of biomedical research, this analysis found that noncommercial entities jointly or exclusively fund almost $90 \%$ of comparative effectiveness studies. ${ }^{8}$ Thus, even if the regulations Tierney et al. propose could protect the integrity of industry-funded research, commercial funders could still set the research agenda, and as a result we worry that the real practice-changing questions may go unanswered.

This is not to suggest, of course, that non-commercially funded academic research is perfect. Academic researchers have biases as well, such as a desire to publish attentiongrabbing findings or to satisfy the political goals of their non-commercial funders. However, it is clear that commercial interests have historically had a deleterious effect on both the integrity and focus of clinical research above and beyond the biases inherent in academic research.

While we sympathize with many of the views expressed in Tierney et al.'s article, we believe the best way to address the needs of all stakeholders - including researchers, commercial entities, patients, and clinicians - would be to create greater separation between commercial funding sources and academic researchers, rather than building bridges between them. Perhaps the best way to do this would be to create an impartial intermediary that would facilitate commercially funded research while ensuring that commercial funders would not have undue influence. Under such a system, if a pharmaceutical company wanted to test a new product, it would provide funding to this neutral entity, which would then solicit bids from independent investigators to study the new product. The independent investigators would have considerable leeway to design the evaluation in a clinically relevant manner. In return, the investigators would commit to expedient completion of their evaluation, with timelines mutually agreed upon by the neutral body and the commercial funder. Regulations would be necessary, for example, to ensure that industry funders did not have undue influence on the neutral intermediary and to hold academic researchers accountable for agreed-upon timelines. And since such a system would require effective collab- oration among the commercial and academic entities and the neutral intermediary, legal and financial policies would need to be in place to guide the partnership. However, we believe that creating an extra degree of separation between commercial funders and academic researchers would dampen potentially detrimental commercial influence on the design and focus of clinical research.

In the current environment, commercial funding will likely continue to be an important source of clinical research funding. But we fear that Tierney et al.'s call for more direct academicindustry collaboration, without clear firewalls, will prove similarly problematic as prior industry-academic collaborations. We believe the best way to ensure that all stakeholders get the research results they need would be to create more separation between those charged with conducting objective research and those with commercial interests in the results.

Corresponding Author: Michael Hochman, MD, MPH; David Geffen School of MedicineUCLA, Los Angeles, CA 90405, USA (e-mail: meh1979@gmail.com).

\section{REFERENCES}

1. Moses H 3rd, Matheson DH, Cairns-Smith S, George BP, Palisch C, Dorsey ER. The anatomy of medical research: US and international comparisons. JAMA. 2015;313(2):174-89.

2. Tierney WM, Meslin EM, Kroenke K. Industry support of medical research: important opportunity or treacherous pitfall? J Gen Intern Med. 2015. doi:10.1007/s11606-015-3495-Z.

3. Bodenheimer T. Uneasy alliance - clinical investigators and pharmaceutical industry. N Engl J Med. 2000;342:1539-1544.

4. Green JB, Bethel MA, Armstrong PW, Buse JB, Engel SS, Garg J, Josse R, Kaufman KD, Koglin J, Korn S, Lachin JM, McGuire DK, Pencina MJ, Standl E, Stein PP, Suryawanshi S, Van de Werf F, Peterson ED, Holman RR, TECOS Study Group. Effect of sitagliptin on cardiovascular outcomes in type 2 diabetes. N Engl J Med. 2015;373(3):232-42.

5. Available at: Drugs.com [Internet]. Januvia Sales Data; Q4, 2013. Available from: http://www.drugs.com/stats/januvia.

6. Kroenke K, West SL, Swindle R, et al. Similar effectiveness of paroxetine, fluoxetine, and sertraline in primary care: a randomized trial. JAMA. 2001;286:2947-2955.

7. American Psychiatric Association. Practice Guideline for the Treatment of Patients with Major Depressive Disorder, Am J Psychiatry, vol. 167(supplement)(10). 3rd ed. 2010:1.

8. Hochman M, McCormick D. Characteristics of published comparative effectiveness studies of medications. JAMA. 2010;303(10):951-8. doi:10. 1001/jama.2010.240. 